\title{
The future of seniors housing in situation of demographic aging of the society - preferences of users and directions of changes
}

\author{
Monika Magdziak \\ Wydziat Architektury, Politechnika Białostocka
}

\begin{abstract}
Summary: Wishing to look deeper into the residential future of seniors, the author tried to identify important global trends influencing the development of the housing environment for the older generation, as well as factors contributing to changes in social service preferences and care requirements. The author examines the issues of Polish demographic and socio-cultural conditions, presents a system of special forms of housing for the elderly and design ideas which have been tested and accepted in other high-developed countries.
\end{abstract}

Key words: housing, elderly, aging society, demography, architecture

\section{Introduction}

In recent years we observe in Poland that the aging process of the population is intensified, more precisely we are seeing a significant increase in the number of older people in relation to younger generations. Transformations in the age structure of Poles take place very quickly, much more intensely than in Western Europe, where this process began much earlier and is even more advanced. In the perspective of these transformations, the greatest and most urgent challenge is to provide assistance and care to dependent seniors, as well as to provide housing and services that will influence the long-term preservation of psychophysical health and functional independence of the elderly. Aging process of polish society creates then new challenges with regard to the social and housing policy, on the extension of special care and housing options for the elderly, both in quantitative and qualitative terms. This issue is currently the subject of ever-increasing discussions and research, especially on the stationary social care for dependent older people.

\section{Objectives, tasks and methods}

In relation to projections that in the coming decades the demographic situation in the European Union will be similar, and that Polish seniors, in terms of needs and preferences, are becoming more and more similar to seniors in other developed countries, the author tried to find patterns and solutions accepted in other countries, which could be helpful in predicting the direction of changes in housing for older people in Poland. Therefore, the main scientific objective has been to bring about world trends. They are a guide to the possible directions of change and development of housing and services that could improve the quality of life for the elderly. The main tasks of the research leading to these objectives are as follows:

- Understanding the demographic and socio-cultural conditions influencing the range of needs and preferences of Polish seniors, 
Characteristics of various housing solutions and amenities for the elderly in Poland and other countries affected by demographic aging,

- Assigning adequate housing solutions to the identified needs and preferences of seniors, as the possible directions of change and development of the system of housing for the elderly in Poland;

In order to obtain the research material, the method of literature research, the method of in-situ research in Polish and foreign housing forms and the interview with senior citizens and persons managing housing forms for the elderly were used.

In this paper, the author presents the current state of conducted research in the form of a brief presentation of Polish conditions, housing models in other high-developed countries and discuss the observed trends, which may provide a basis for identifying possible directions for changes in the housing environment that enhance the quality of life for seniors.

\section{Results}

Demographic conditions - an increase in demand for care services - Demographic projections clearly point to the process of demographic aging of the Polish population since 1967. By 2030 the number of people aged 60 and over will exceed 10 million and will constitute about $27 \%$ of the population. This is due, among others, from longer life expectancy and crossing the threshold of old age by the post-war baby boomers [Synak 2003].

The systematic prolongation of life is synonymous with the prolongation of the old age. This also affects the increase in the number of dependents people who require some form of care or assistance and adapted environment. According to GUS data, the number of people aged 80 and over - nearly 1.5 million in 2013 - will rise by more than double to over 3.5 million in 2050. Taking into account the statistical participation of people with a high level of disability, it can be predicted that if the quality and lifestyle of Poles will not be changed in the future, then in 2050 more than 1 million, people over 80 years old and over 1.5 million between 60 and 80 years old will be seriously dependent and will need permanent, specialized care. There will also as much people with medium level of physical limitations, it means people who need some form of support in their daily activities. Together, this gives almost 5 million people who will need adapted or special housing and some form of assistance or care [GUS 2014]. At present there is a decrease in the number of family members who can take care of dependents seniors. The decrease in fertility leads to the reversal of the traditional family structure and the increase in the demand for formal care [Bień 2001].

Socio-cultural determinants - economic transformations and change of relations between members of the family - Polish society belongs to the group of traditional societies, with a strong family position and relationships between generations. Care for elderly parents is treated (or at least it was so far) as an obvious duty, and the use of formal care as the ultimate solution. Largely, such attitudes are influenced by bad opinion about Polish social care homes, for which there is no reasonable alternative.

In recent years, however, the perception of the state as the only entity responsible for providing care to seniors has changed. At present, more importance is given to non-public sectors (market and social sectors). At the same time, the Polish state continues to play the most important role as the legislator. Nevertheless, the role and competencies of other developing sectors, especially non-governmental, commercial and non-formal, continue to grow. This gives Poland in the coming years a chance to get closer to the "old European Union" countries.

The cultural model of care is also influenced by the transformations of family life that take place in modern times. The level and quality of contacts between representatives of successive generations is currently being loosened. The effect of such a state is the migration of the younger generation and the large distance of residence. [Dyczewski 1994] The foreign migration flow of the younger generation is now greater than assumed before Poland's accession to the European Union. However, it can be assumed that some of these people will return to Poland after retirement, that is, when they themselves will need support in daily life. Moreover, they will probably be looking for housing and care homes similar to those in other high-developed countries.

Positive changes are also observed especially in urban areas. These changes are primarily due to the fact that younger generations of seniors are better educated, healthier and wealthier [Friedland, Summer 1999]. The good situation of younger seniors is mainly a result of the progress of medicine, physical fitness, greater 
activity and self-fulfilment [Kowaleski, Pietruszek 2006]. It can be expected that as seniors from other highly developed countries, these people may after retirement seek housing solutions that promote activity, social interaction, the pursuit of their own passions and interests, or education. This is confirmed by the growing popularity of Third Age Universities, among the younger groups of Polish seniors.

\section{Housing solutions for the elderly}

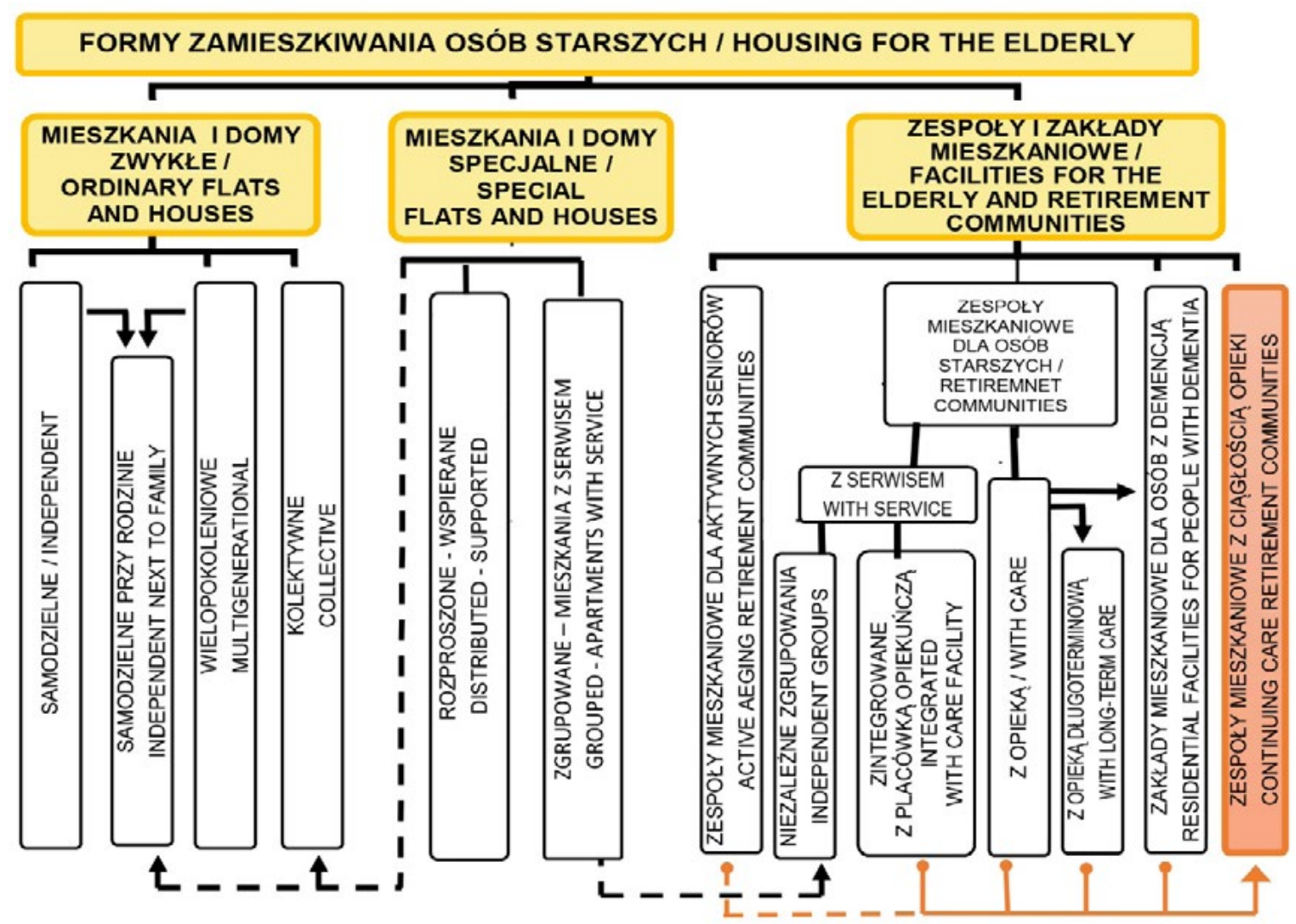

Fig. 1. Housing for the elderly - division. Symbols: dotted lines indicate the possible relationship of a housing form with another group, orange highlighting - special case of residential complexes with continuity of care which consist of several forms of housing for the elderly, indicated by an orange line. Source: Author's work

Formy zamieszkiwania osób starszych - podział. Oznaczenia: linią przerywaną oznaczono możliwe powiązania danej formy zamieszkiwania z inną grupą, kolorem pomarańczowym wyróżniono szczególny przypadek zespołów mieszkaniowych z ciągłością opieki, które składają się z kilku form mieszkaniowych dla osób starszych, wskazanych pomarańczową linią. Źródło: opracowanie własne.

In most of the highly developed countries, affected by the aging of society, in addition to the services and systems of home care, there are various forms of housing with care and housing with a service for the elderly. These objects, both in their form and way of functioning, differ significantly from the Polish model of a care facility, based on models derived from health care facilities. As a result of the search for housing patterns, the classification of recognized forms of inhabiting elderly people is divided into three basic groups: ordinary flats and houses, special apartments and houses, Facilities for the elderly and retirement communities. Fig. 1 presents the systematic approach in which all the recognized forms of housing for elderly, recognized in Poland or other high-developed countries, were taken into account. 


\section{Discussion - trends and possible development in housing for elderly}

Staying in your current place of residence - This preference is usually the result of attachment to a known place, but also the reluctance and sense of uncertainty that accompanies the change of environment. In addition, older people value close ties and close contact with family and friends living in the vicinity, and also show emotional attachment to the home and land inherited from their ancestors [Kandel, C. Adamec 2003]. This preference brings some problems. In case of the elderly with motor disability as well as in the early stages of dementia, staying in inadequate flats provides many difficulties, and existing barriers lead to reduced security and isolation of seniors from social life. Modernization of existing housing, both in terms of access to housing and interior adjustment, can largely solve many of these difficulties, but it is not always possible for technical and financial reasons.

Often the problem is also the inhabitation of older people in oversized flats and single-family houses. The cost of maintaining such properties is a considerable financial burden, often exceeding the real economic potential of the elderly. Of the interviews and questionnaires conducted by the author among independent seniors, $87 \%$ indicated economic factors as the main stimulus to change the place of residence.

"Aging-in-place" - the idea of the longest stay of the elderly in the place of residence has been extended to the idea of continuing to live in a familiar environment (for example in the same district) and moving to nearby adapted housing forms for older people. This solution avoids the need for subsequent removals and allows older people to remain in a familiar and environmentally-friendly home, regardless of their state of health. [Christner-Lile 2011].

Originally, this idea was related to living in specialized retirement communities complemented by services and various forms of housing with care, located within one campus. These housing communities provide continuity of care at various levels. Initially these were large isolated urban communities, due to the cost of land located outside the city, the so-called Age-Restricted Communities, in which only seniors lived. With the development of the idea of integrating generations, developers began to form dispersed, smaller groups of such housing forms which function in integration with local community [Perkins 2004].

Independent living of seniors - This tendency refers to the negation of the model of a multigenerational family and is due to the weakening of family relationships caused by the younger generation's lifestyle, but also the need for self-fulfilment of seniors [Schaie 2003]. This situation is also related to the fact that multigenerational living, together with the family of children, is not necessarily connected with greater satisfaction of life and reduction of loneliness. In Northern Europe (Scandinavia, Netherlands), the elderly tend to live in care facilities, while experiencing much more satisfaction with life and less feeling of alienation than seniors in Poland. These differences are not affected by cultural differences and tradition, but through the level of activity and independence of the elderly [OECD, 2003].

The preferred housing autonomy of seniors is often conditioned with a high level of family contacts, mainly through living of the elderly in the immediate vicinity of their children or through independent living directly with the family of children, for example in a separate part of the house with independent entrance. According to such expectations, there is a tendency to include in ready-made houses design offer, so-called two-family houses. If parents of adult children start to need help or care, instead of living together, they can create better conditions for more frequent contact. Moreover, in many cases, the formation of multi-generational families is mainly due to economic reasons, which often lead to tensions and conflicts. On the other hand, caring for the elderly is often a cumbersome and hard work that leads to the frustration and weariness of carers. The separate places of residence of older people and their children who are located nearby can stimulate more frequent visits and improve the level of contacts and help between the generations.

Collective forms - cohabitation of unrelated people - This form of residence has been popular in the Scandinavian countries for a long time. Now it is becoming increasingly popular in other European countries. The main reason for these changes is the previously mentioned phenomenon of loosening of family ties. With the changes in family life, the number of small households increases. On the other hand, economic considerations related to the relatively high costs of maintaining homes contribute to an increase in the tendency of cohabitation of unrelated people. This phenomenon is also more frequent in Poland. This trend is illustrated by GUS data, which clearly indicate a decrease in the number of single-family households, at the root of the proportional growth of non-family households [GUS 2011]. This trend is particularly interesting in the context 
of declining birth rates and increasing migration. Both factors lead to a rising number of elderly, who are single or childless. These people both in the earlier and later ages can express a desire to live together in collective housing communities [Durrett 2009].

Reluctance to live in institutional care facilities - The main reason for the negative attitude towards the Social Welfare Houses in Poland is the lack of privacy and personal autonomy of the inhabitants. Despite this trend, Care Homes will certainly not disappear. On the contrary, in Poland, where there is still a great shortage of such facilities, we can expect that as the number of older people increases, the number of care facilities will also increase. However, today many countries are taking actions to reduce the number of people living in longterm care institutions. Some countries have developed special programs to replace them with various forms of housing with service for the elderly. The decline in interest in living in institutional settings will probably require additional services in local environments. Moreover, in the case of construction of new buildings for the elderly, the idea of purpose-build housing appears. These are buildings designed and constructed specifically for the elderly. This idea, in spite of the widespread practice in Poland of modernizing and transforming existing old buildings (for example, workers' hotels) into nursing homes, is a key point in the fact, that already in the course of design processes we should think about future users and their needs. This is the only way to meet the expectations of a particular group of inhabitants. The concept of special buildings for older people provides opportunities to improve not only the housing standard, but also to improve the quality of life, create conditions that activate, integrate and improve the psychophysical condition of seniors in a well-designed housing environment [Carstens 1993]. Of course, this idea is accompanied by other design ideas, such as the flexibility of plan, the barrier-free design and universal design, which seem to be a necessity in a demographically changed Poland.

Integration of residential space and various systems of modern technologies - Technological progress is today a hope for a better and easier life for the elderly. In particular, the development of modern forms of communication and information delivery has the potential to contribute to easier and faster monitoring of health, providing information and advice as well as education and improving family relationships through distance communication. Home automation is designed to facilitate the mobility of people with disabilities, to ensure the safety of people with memory and cognitive disorders, and to improve contacts and access to services for seniors living outside large agglomerations [Harper 2003]. However, technological progress brings with it the danger of a decline in social interaction. Next, we will have to eliminate local services and replace them with virtual ones, and this can have harmful social consequences, especially for people without access to computers and other new technologies. Also, in the area of health services, even with the support of developing technologies, skilled staff will always be needed, and the lack of nursing staff in Poland will probably be felt in the near future.

Change in consumption structure - Probably, increase in the number of older people and generations coming into old age, will contribute to increasing health care expenses. More people will benefit from the help of doctors, clinics and hospitals. At the same time, the number of nursing homes and new forms of housing for older people will increase. Observing the trends presented in other countries, probably the tourist consumption of Polish seniors will also increase. Another issue is Active Aging - leisure, recreation, sport promotion and healthy lifestyle are the global trends of the new consumer sector [Śniadek 2006]. The desire to retain time and maintain youth has led to the emergence of Active Adult Communities that have become popular in the United States. Over there, seniors can benefit from education, services to improve their overall physical condition, entertainment and help to fill their free time after retirement. Moreover, in the spirit of lifelong learning, many seniors are inclined to return to learning. This is why the number of older people is looking for different forms of entertainment and education, and Third Age Universities and housing developments in their vicinity are becoming more and more popular in western countries [Suchman 2001].

\section{Conclusions}

The trends and experiences of other countries should be taken into account when discussing housing and social solutions for future seniors. They can have a significant impact on shaping the housing environment of the future generation of older people also in Poland. Some of them are obvious and certain, others less. Many of 
these tendencies reflect the changes and demographic processes of an aging society. Although they are not always directly related to the theme of the housing environment, they influence changes in living patterns, housing needs and preferences of seniors.

\section{Literature}

[1] Bień B., 2001: Starość pod ochroną, Old age under protection, Kraków, 7,101-102.(In Polish)

[2] Carstens D.,1993: Site Planning and Design for the Elderly: Issues, Guidelines, and Alternatives, Wiley, 1.

[3] Christner-Lile D., 2011: Aging in Place: Safely Living in Your "Home Sweet Home" Until You're 100+, Tate Publishing, United States of America, 17-19.

[4] Durrett C., 2009: The Senior Cohousing Handbook - A Community Approach to Independent Living, New Society Publishers, Canada, xi.

[5] Dyczewski L.,1994: Old people and old age in society and culture, KUL, Lublin, 51. (In Polish)

[6] Friedland R.B., Summer L., 1999: Demography Is Not Destiny, National Academy on an Aging Society, Washington. 29.

[7] GUS 2011, Households and families, National Census of Population and Housing. (In Polich)

[8] GUS, 2014: Population forecast for 2014-2050, Warsaw. (In Polich)

[9] Harper R., 2003: Inside the Smart Home: Ideas, possibilities and methods, Springer, 28

[10] Kandel J., Adamec C., 2003: The Encyclopedia of Senior Health and Well-being, Infobase Publishing, 145.

[11] Kowaleski J.T., Pietruszek M., 2006: The place of older people in demographic structure of inhabitants of Poland, [in:] Old people in Polish society in the first decades of the 21st century, Publishing House of University of Lodz, 29. (In Polich)

[12] OECD, 2003: Ageing, Housing and Urban Development, Organisation for Economic Co-operation and Development, Paris.

[13] Perkins E., 2004: Building Type Basics for Senior Living, Wiley\&Sons, United States of America, 97-98.

[14] Schaie K., 2003: Aging Independently: Living Arrangements and Mobility, Springer Publishing Company, 102.

[15] Suchman D., Becker W., 2001: Developing Active Adult Retirement Communities, Urban Land Institute, Washington, 2-5B.

[16] Śniadek J., 2006: Age of seniors - a challenge for tourism and leisure industry, [in:] Studies of Physical Culture and Tourism, Vol. 13, 103.

The research was carried out within the framework of work No. SNAA/2/16 and funded by the Ministry of Science and Higher Education. 